\title{
Genetic relatedness between Japanese and European isolates of Clostridium difficile originating from piglets and their risk associated with human health
}

\section{Masaru Usui ${ }^{1}$, Yukie Nanbu' ${ }^{1}$, Kentaro Oka ${ }^{2}$, Motomichi Takahashi ${ }^{2,3}$, Takashi Inamatsu ${ }^{4}$, Tetsuo Asai ${ }^{5}$, Shigeru Kamiya ${ }^{3}$ and Yutaka Tamura ${ }^{1}$ *}

${ }^{1}$ Laboratory of Food Microbiology and Food Safety, Department of Health and Environmental Sciences, School of Veterinary Medicine, Rakuno Gakuen University, Hokkaido, Japan

${ }^{2}$ Miyarisan Pharmaceutical Co., Ltd., Tokyo, Japan

${ }^{3}$ Department of Infectious Diseases, Kyorin University School of Medicine, Tokyo, Japan

${ }^{4}$ Department of Infectious Diseases, Tokyo Metropolitan Geriatric Hospital, Tokyo, Japan

${ }^{5}$ The United Graduate School of Veterinary Sciences, Gifu University, Gifu, Japan

\section{Edited by:}

Evangelos Giamarellos-Bourboulis, University of Athens Medical School, Greece

\section{Reviewed by:}

V. K. Viswanathan, University of Arizona, USA

Li Xu, Cornell University, USA

\section{${ }^{*}$ Correspondence:}

Yutaka Tamura, Laboratory of Food

Microbiology and Food Safety,

Department of Health and

Environmental Sciences, School of Veterinary Medicine, Rakuno Gakuen University, 582 Midorimachi, Bunkyodai, Ebetsu, Hokkaido 069-8501 Japan

e-mail: tamuray@rakuno.ac.jp
Clostridium difficile colonization in pig intestine has been a public health concern. We analyzed $C$. difficile prevalence among piglets in Japan to clarify their origin and extent of the associated risk by using molecular and microbiological methods for both swine and human clinical isolates and foreign isolates. C. difficile was isolated from 120 neonatal piglet fecal samples. Toxin gene profile, antimicrobial susceptibilities, PCR ribotype, and multiple-locus variable-number tandem-repeat analysis (MLVA) type of swine isolates were determined and compared with those of human clinical and foreign isolates. One-hundred C. difficile strains were isolated from $69(57.5 \%)$ samples, and 61 isolates $(61 \%)$ were toxin gene-positive. Some isolates were resistant to antimicrobials, contributing to antibioticassociated diarrhea by $C$. difficile. These results suggest that $C$. difficile, prevalent among Japanese pigs, is a potential risk for antibiotic-associated diarrhea. Furthermore, PCR ribotype 078 (12 isolates), which has been linked to multiple outbreaks worldwide, was the third-most frequently isolated of the 14 PCR ribotypes identified. Moreover, MLVA revealed that all 12 PCR ribotype 078 isolates were genetically related to European PCR ribotype 078 strains found in both humans and pigs. To date, in Japan, many breeding pigs have been imported from European countries. The genetic relatedness of $C$. difficile isolates of Japanese swine origin to those of European origin suggests that they were introduced into Japan via imported pigs.

\section{Keywords: antimicrobial resistance, Clostridium difficile, MLVA, PCR ribotype 078, piglets}

\section{INTRODUCTION}

Clostridium difficile is a gram-positive spore-forming anaerobic bacterium that causes antibiotic-associated diarrhea and pseudomembranous colitis in humans. Most pathogenic C. difficile strains produce two structurally similar toxins, toxin $\mathrm{A}$, and toxin $\mathrm{B}$, the main virulence determinants associated with $C$. difficile infection. C. difficile is often isolated from patients and foodproducing animals (Keessen et al., 2011). Although zoonotic transmission remains speculative, meat products could be a common source of C. difficile infection in humans, and food-producing animals could also serve as a reservoir.

In the past decade, $C$. difficile infections have become more common and more severe in developed countries, including Japan (Rupnik etal., 2009; Honda et al., 2014). Recent reports have demonstrated that the increase in $C$. difficile burden has been driven by a rapid change in the global epidemiology with the emergence of an epidemic strain of $C$. difficile. The strain PCR ribotype 027 (BI/NAP1) was detected initially in North America, and was observed subsequently in European countries, Australia, and some Asian countries (Richards et al., 2011; Collins et al., 2013; Knight et al., 2013). In addition, the prevalence of PCR ribotype 078, a strain commonly found in pigs, has increased since 2006 and is currently one of the most common types in European countries (Bauer et al., 2011). Some reports have highlighted the high-level relatedness that exists between $C$. difficile PCR ribotype 078 isolates from both human and swine origins by using highly discriminative typing methods such as multiple-locus variable-number tandemrepeat analysis (MLVA; Debast et al., 2009; Bakker et al., 2010). In Japan, PCR ribotype 027 has only been observed in sporadic cases and PCR ribotype 078 has not been detected, unlike in Europe and North America (Collins et al., 2013). PCR ribotype 018 (smz) is the most prevalent isolate detected from human cases of $C$. difficile infection in Japan (Collins et al., 2013). To evaluate the risk to human health, it is important to determine bacterial properties of swine C. difficile isolates, such as toxigenicity, genotype, and antimicrobial susceptibility, and compare them with those of human isolates.

The purpose of this study was to clarify the risk to human health associated with $C$. difficile isolates present in the swine population of Japan. We have previously attempted to isolate $C$. difficile from 
250 slaughter pigs; however, C. difficile was isolated from only two fecal samples (Asai et al., 2013). C. difficile is more frequently isolated from neonatal piglets, rather than slaughter pigs (Hopman et al., 2011). In addition, there is no clear link between $C$. difficile isolation and neonatal porcine diarrhea (Alvarez-Perez et al., 2009). Therefore, we isolated $C$. difficile from clinically normal piglets to elucidate the present status of $C$. difficile in Japan. We assessed the toxigenicity and antimicrobial susceptibility of the C. difficile isolates, and determined the relatedness of $C$. difficile that originated from piglets, human clinical isolates, and foreign isolates by analyzing their molecular characteristics.

\section{MATERIALS AND METHODS}

\section{BACTERIAL STRAINS AND FECAL SAMPLES}

A total of 120 fecal specimens were collected from neonatal piglets less than 20 days of age. These samples were collected at 12 farms (10 piglets from different farrowing sows/farm) during JuneAugust 2012 in seven different prefectures of Japan. The piglets did not exhibit symptoms of diarrhea at the time of sampling.

Two isolates of $C$. difficile obtained from slaughter pigs in Japan (Asai et al., 2013) were used in this study. Seventy-three clinical isolates of $C$. difficile that were obtained between 2002 and 2005 at two Tokyo hospitals (Oka et al., 2012) were also used in this study to compare their antimicrobial susceptibilities and genetic relatedness with the swine isolates. C. difficile strains 9689, 43593, 700057, BAA-1870, and BAA-1875 were obtained from the American Type Culture Collection (ATCC; Manassas, VA, USA) to serve as reference strains.

\section{CULTURE MEDIA}

Clostridium difficile isolated from fecal samples that were treated with alcohol for spore selection as described previously (Asai et al., 2013), was cultured on cycloserine-cefoxitin-mannitol agar
(CCMA)-Ex (Nissui Pharmaceutical, Tokyo, Japan) at $37^{\circ} \mathrm{C}$ for 36-48 h under anaerobic conditions. Isolated colonies were purified by restreaking onto CCMA-Ex followed by anaerobic incubation as indicated above. For each fecal sample, a maximum of three colonies were identified as $C$. difficile based on colony morphology, and were then analyzed further.

\section{IDENTIFICATION AND TOXIN GENE DETECTION}

DNA was extracted using a commercial kit (InstaGene Matrix, BioRad, Hercules, CA, USA) according to the manufacturer's instructions. Polymerase chain reaction (PCR) with a specific primer set (Table 1; Kikuchi et al., 2002) was used to confirm bacterial identification. The presence of genes encoding toxin $A, B$, and binary toxin ( $t c d A, t c d B$, and $c d t A / B$, respectively) was analyzed using multiplex PCR as described previously (Persson et al., 2008). Primer sequences are listed in Table 1. To investigate the $3^{\prime}$ end deletion in $t c d A$, a supplemental PCR was performed as described previously (Kato et al., 1999) using the primers (Table 1).

\section{PCR RIBOTYPING}

Polymerase chain reaction ribotyping was performed as described previously (Stubbs et al., 1999; Oka et al., 2012). Briefly, the volume of the PCR mixture was downscaled from 50 to $15 \mu \mathrm{L}$, and the amplified PCR products were concentrated to a final volume of approximately $10 \mu \mathrm{L}$ by heating at $75^{\circ} \mathrm{C}$ for $90-120 \mathrm{~min}$. Electrophoresis in 3\% Metaphor agarose (Lonza Rockland Inc., Basel, Switzerland) at a constant voltage of $120 \mathrm{~V}$ for $4 \mathrm{~h}$ was used to separate the PCR products. The PCR ribotyping banding patterns were analyzed using the BioNumerics program (Applied Maths, SintMartens-Latem, Belgium). Similarity and diversity were assessed by applying the Dice coefficient. Cluster analysis was performed using the Unweighted Pair Group Method with Arithmetic Mean algorithm.

Table 1 | Primers used in the present study.

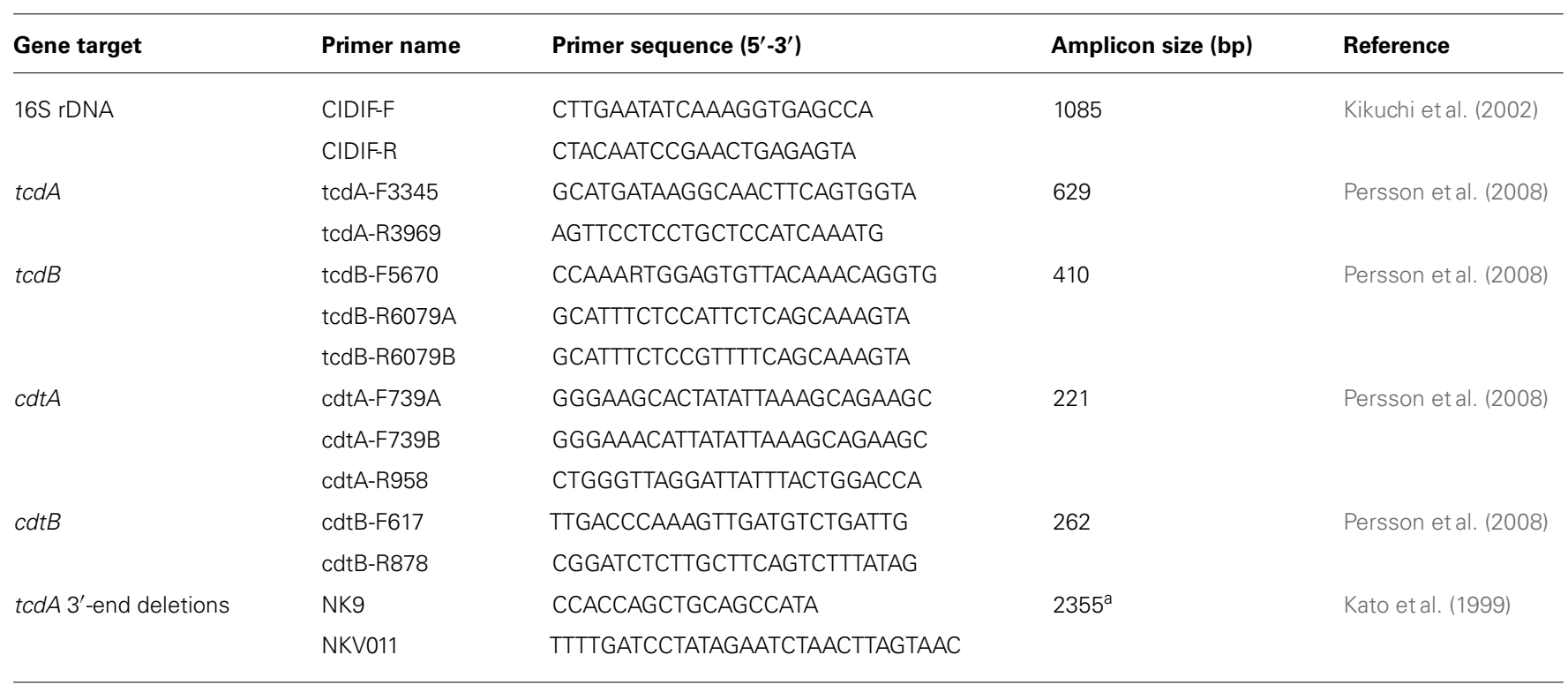

a Amplicon size when no deletion was present. 


\section{ANTIMICROBIAL SUSCEPTIBILITY TESTING}

We performed minimal inhibitory concentration (MIC) determinations using the agar dilution method according to the Clinical Laboratory Standards Institute [CLSI] (2007) guidelines. Susceptibility to vancomycin, metronidazole, clindamycin, ceftriaxone, erythromycin, and ciprofloxacin (Sigma-Aldrich, St. Louis, MO, USA) was tested. The resistance breakpoints of metronidazole, clindamycin, and ceftriaxone adopted were those defined by the CLSI guidelines (Clinical Laboratory Standards Institute [CLSI], 2007). The breakpoints for vancomycin, erythromycin, and ciprofloxacin, which are not defined by the CLSI guidelines, were chosen as described in a previous report Oka et al. (2012). C. difficile ATCC700057 was used as a quality control strain. Antimicrobial susceptibility of 73 human clinical isolates of $C$. difficile was determined by the E-test Oka et al. (2012) and the agar dilution method to compare the MICs of swine and human clinical isolates.

\section{CHARACTERIZATION OF PCR RIBOTYPE 078 ISOLATES}

The toxinotype of all PCR ribotype 078 isolates was determined by the method described by Rupnik et al. (2001). The $t c d C$ sequence of all PCR ribotype 078 isolates was determined as described by Spigaglia and Mastrantonio (2002).

\section{MULTIPLE-LOCUS VARIABLE-NUMBER TANDEM-REPEAT ANALYSIS (MLVA)}

The MLVA of all PCR ribotype 078 isolates was determined by the optimized MLVA method based on six loci (Bakker et al., 2010). PCR was carried out as described by Bakker et al. (2010). To confirm the number of tandem repeats, the PCR product was directly sequenced. The amplified product was purified with FastGene Gel/PCR Extraction Kit (Nippon Genetics, Tokyo,
Japan) and sequenced in both directions using the same primers employed in the PCR. Nucleotide sequences were determined using the BigDye Terminator, version 3.1, Cycle sequencing kit with an automated DNA sequencer (ABI 3130; Applied Biosystems, Foster City, CA, USA). The number of tandem repeats at each locus was manually determined using the BioEdit software (http://www.mbio.ncsu.edu/bioedit/bioedit.html). The motif copy numbers in the tandem array were imported into the BioNumerics software (Applied Maths) and a minimum-spanning tree was generated using the categorical coefficient of the software. We compared the MLVA profiles of our PCR ribotype 078 isolates and the foreign PCR ribotype 078 isolates derived from pigs and humans (Bakker et al., 2010).

\section{RESULTS}

Isolation of $\boldsymbol{C}$. difficile FROM PIGLET FECAL SAMPLES

Fecal samples from 120 piglets were analyzed, and $C$. difficile was isolated only from a subset of those piglets. When two or three isolates from a fecal sample exhibited the same PCR ribotype and antimicrobial susceptibility, they were considered to be a single isolate. Thirty-nine isolates were derived from 39 samples, 58 isolates were derived from 29 samples (two isolates from each sample), and three isolates were derived from one sample (three isolates from the single sample). In total, $100 \mathrm{C}$. difficile isolates were identified. C. difficile was isolated from 69 (57.5\%) of the 120 samples obtained from 11 (91.7\%) of the 12 farms (Table 2 ).

\section{TOXIN GENE PROFILE}

The toxin profile of the $C$. difficile isolates was examined by PCR. Of the 100 isolates of $C$. difficile, $61.0 \%(61 / 100)$ were positive for $t c d A$ and $t c d B$ (Toxin $A^{+} B^{+}$), among which $42.6 \%(26 / 61)$ were also positive for the binary toxin genes $\left(c d t A\right.$ and $c d t B ; \mathrm{CDT}^{+}$;

Table 2 | Isolation and toxin gene profile of Clostridium difficile from Japanese piglets.

\begin{tabular}{|c|c|c|c|c|c|c|c|}
\hline \multirow[t]{2}{*}{ Farm } & \multirow{2}{*}{$\begin{array}{l}\text { Location of } \\
\text { prefecture }\end{array}$} & \multirow[t]{2}{*}{ Samples } & \multirow{2}{*}{$\begin{array}{l}\text { No. of positive } \\
\text { samples }\end{array}$} & \multirow[t]{2}{*}{ No. of isolates } & \multicolumn{2}{|c|}{ Toxin $A^{+} B^{+}$} & \multirow[t]{2}{*}{ Toxin $\mathrm{A}^{-} \mathrm{B}^{-} \mathrm{CDT}^{-}$} \\
\hline & & & & & $\mathrm{CDT}^{+}$ & $\mathrm{CDT}^{-}$ & \\
\hline$A$ & Hokkaido & 10 & 9 & 11 & 0 & 10 & 1 \\
\hline$B$ & Hokkaido & 10 & 7 & 8 & 0 & 8 & 0 \\
\hline C & Hokkaido & 10 & 8 & 10 & 10 & 0 & 0 \\
\hline $\mathrm{D}$ & Hokkaido & 10 & 7 & 13 & 0 & 0 & 13 \\
\hline$E$ & Hokkaido & 10 & 9 & 18 & 0 & 17 & 1 \\
\hline $\mathrm{F}$ & Miyagi & 10 & 0 & 0 & 0 & 0 & 0 \\
\hline G & Miyagi & 10 & 7 & 10 & 5 & 0 & 5 \\
\hline $\mathrm{H}$ & Yamagata & 10 & 3 & 3 & 0 & 0 & 3 \\
\hline I & Fukushima & 10 & 5 & 7 & 0 & 0 & 7 \\
\hline J & Tochigi & 10 & 4 & 4 & 4 & 0 & 0 \\
\hline K & Chiba & 10 & 7 & 9 & 6 & 0 & 3 \\
\hline $\mathrm{L}$ & Gifu & 10 & 3 & 7 & 1 & 0 & 6 \\
\hline Sub Total & & & & & 26 & 35 & \\
\hline Total & & 120 & $69(57.5 \%)$ & 100 & 61 & & 39 (39.0\%) \\
\hline
\end{tabular}


Table 2). $3^{\prime}$ end deletion in $t c d A$ was not detected in all 61 strains positive for $t c d A$. Thirty-nine isolates $(39.0 \%)$ were negative for $t c d A, t c d B, c d t A$, and $c d t B$ (Toxin $\mathrm{A}^{-} \mathrm{B}^{-} \mathrm{CDT}^{-}$). One isolate of $C$. difficile derived from a slaughter pig (12EN) was also positive for $t c d A$ and $t c d B$ (Toxin $\mathrm{A}^{+} \mathrm{B}^{+}$) by the multiplex PCR method (Persson etal., 2008), although the isolate was only positive for $t c d B$, as determined using the primer set described by Kato et al. (1998). A deletion in $t c d A$ that was complementary the NK11 primer, which was used for amplification of $t c d A$ gene in the previous report Asai et al. (2013), was observed. The isolate of 12EN was also positive for binary toxin genes. The other isolate derived from a slaughter pig (134C1) was negative for toxin $\mathrm{A}, \mathrm{B}$, and binary toxin (Toxin $\mathrm{A}^{-} \mathrm{B}^{-} \mathrm{CDT}^{-}$).

\section{ANTIMICROBIAL SUSCEPTIBILITY}

$\mathrm{MIC}_{50} \mathrm{~s}, \mathrm{MIC}_{90} \mathrm{~s}$, and the range of MICs of vancomycin, metronidazole, clindamycin, ceftriaxone, erythromycin, and ciprofloxacin for the $100 \mathrm{C}$. difficile isolates were determined (Table 3). All isolates were susceptible to vancomycin and metronidazole. Resistance against clindamycin, ceftriaxone, erythromycin, and ciprofloxacin were found in $59,6,46$, and $75 \%$ of the isolates, respectively. Of the 61 toxigenic $C$. difficile isolates (Toxin $\mathrm{A}^{+} \mathrm{B}^{+}$), the incidence of resistance to clindamycin, ceftriaxone, erythromycin, and ciprofloxacin was $71,10,43$, and $74 \%$, respectively. The percentage of resistant isolates derived from piglets against all antimicrobials, particularly ceftriaxone, was lower than that clinically isolated from humans (Oka etal., 2012).

\section{GENOTYPING}

All 100 isolates were PCR ribotypeable and resolved into 14 PCR ribotypes (Figure 1; Table 4). The major PCR ribotypes of $C$. difficile isolates were P1 (34 isolates), P2 (20 isolates), and P3 (12 isolates). The banding patterns of PCR ribotype P2 and PCR ribotype P3 was identical to that of ATCC 700057 (PCR ribotype 038) and ATCC BAA-1875 (PCR ribotype 078), respectively. The banding patterns of $134 \mathrm{C} 1$ and $12 \mathrm{EN}$, which were derived from slaughter pigs (Asai etal., 2013), were identical to PCR ribotype $\mathrm{P} 2$ and $\mathrm{PCR}$ ribotype $\mathrm{P} 3$, respectively. None of the PCR ribotypes of $C$. difficile isolates from piglets were identical to those from human clinical isolates in Japan (Oka et al., 2012) or the reference strains C. difficile ATCC 9689 (PCR ribotype 001), ATCC 43593 (PCR ribotype 060), and ATCC BAA-1870 (PCR ribotype 027).

\section{CHARACTERIZATION OF PCR RIBOTYPE 078 ISOLATES}

All 12 C. difficile PCR ribotype 078 strains belonged to toxinotype V. All 12 C. difficile PCR ribotype 078 strains were found to contain a 39-base pair deletion in the toxin regulator gene $(t c d C)$. One isolate of $C$. difficile PCR ribotype 078 derived from a slaughter pig (12EN) belonged to toxinotype VI. This isolate also contains a 39-base pair deletion in $t c d C$.

\section{MLVA}

In a previous report, 102 and 56 C. difficile PCR ribotype 078 strains of human and swine origins, respectively, from four European countries were investigated by MLVA (Bakker et al., 2010). The largest genetically related clusters (GCs) contained 103 strains, encompassing 47 swine strains and 56 human strains. In this study, all C. difficile PCR ribotype 078 strains from 12 piglets and one slaughter pig also belonged to the largest GCs (Figure 2; Table 5).

\section{DISCUSSION}

We demonstrated the high prevalence of $C$. difficile in clinically normal piglets $(57.5 \%)$, despite the previous isolation of only two strains from slaughter pigs $(0.8 \%)$ in Japan (Asai et al., 2013). Hopman et al. (2011) suggested that piglets acquire C. difficile shortly after birth. A previous study revealed that piglets become infected with $C$. difficile through contamination of the environment in the farrowing crates (Hopman et al., 2011). A significant reduction in the rate of colonization with $C$. difficile with age has also been reported Norman et al. (2009). The PCR ribotypes of two isolates from slaughter pigs (Asai et al., 2013) belonged to that of the two dominant PCR ribotypes detected among piglet strains

Table 3 | Antimicrobial susceptibility of Clostridium difficile piglet isolates and human clinical isolates.

\begin{tabular}{|c|c|c|c|c|c|c|c|c|c|}
\hline \multirow[b]{3}{*}{ Antimicrobials } & \multirow{3}{*}{$\frac{\text { MIC }(\mu \mathrm{g} / \mathrm{mL})}{\text { Break point }}$} & \multicolumn{4}{|c|}{ Piglet } & \multicolumn{4}{|c|}{ Humanc } \\
\hline & & \multicolumn{3}{|c|}{$\operatorname{MIC}(\mu \mathrm{g} / \mathrm{mL})$} & \multirow{2}{*}{$\begin{array}{l}\text { No. of resistant } \\
\text { isolates }(n=100)\end{array}$} & \multicolumn{3}{|c|}{$\operatorname{MIC}(\mu \mathrm{g} / \mathrm{mL})$} & \multirow{2}{*}{$\begin{array}{l}\text { No. of resistant } \\
\text { isolates }(n=73\end{array}$} \\
\hline & & $50 \%$ & $90 \%$ & Range & & $50 \%$ & $90 \%$ & Range & \\
\hline Vancomycin & $\geq 32^{a}$ & 1 & 2 & $1-4$ & 0 & 0.5 & 1 & $0.06-2$ & 0 \\
\hline Metronidazole & $\geq 32^{b}$ & 0.5 & 8 & $0.125-8$ & 0 & 0.25 & 0.25 & $<0.06-0.25$ & 0 \\
\hline Clindamycin & $\geq 8^{b}$ & 8 & 256 & $0.25->256$ & $59(59.0 \%)$ & 256 & $>256$ & $0.125->256$ & $64(87.7 \%)$ \\
\hline Ceftriaxone & $\geq 64^{b}$ & 16 & 32 & $2->256$ & $6(6.0 \%)$ & 256 & 256 & $0.125->256$ & 62 (84.9\%) \\
\hline Erythromycin & $\geq 8^{\mathrm{a}}$ & 2 & $>256$ & $1->256$ & $46(46.0 \%)$ & $>256$ & $>256$ & $<0.125->256$ & $61(83.6 \%)$ \\
\hline Ciprofloxacin & $\geq 4^{a}$ & 8 & 8 & $0.5-128$ & 75 (75.0\%) & 64 & 64 & $0.125-64$ & $68(93.2 \%)$ \\
\hline
\end{tabular}

MIC, minimum inhibitory concentration.

aThe value was the previous report break point (Oka etal., 2012).

bThe value was the CLSI break point (Clinical Laboratory Standards Institute [CLSI], 2007).

cThese isolates were isolated in the previous report Oka etal. (2012). 


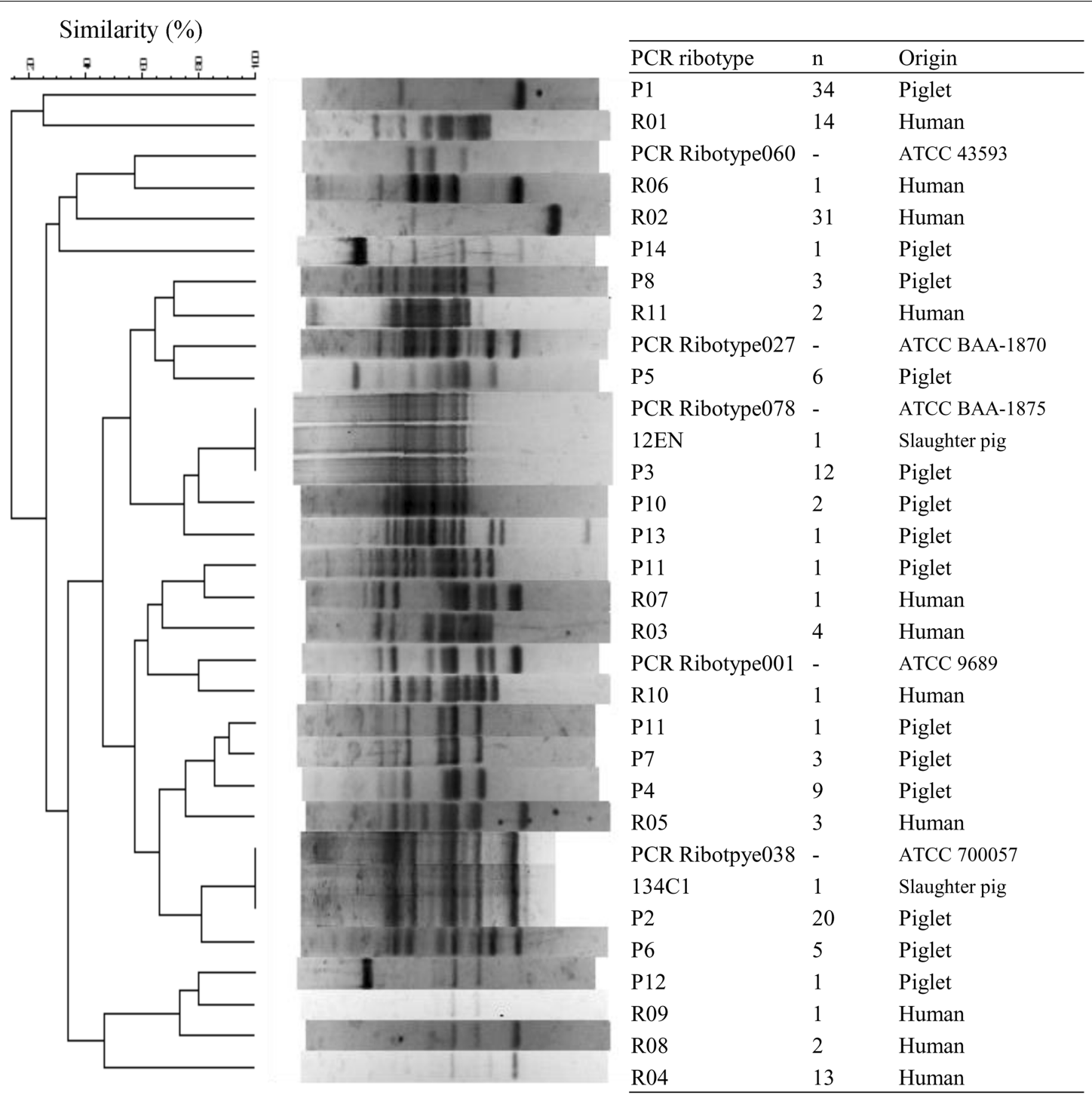

FIGURE 1|Polymerase chain reaction (PCR) ribotype profiles of Clostridium difficile strains isolated from piglets, slaughter pigs, and humans. PCR ribotyping pattern analysis was performed by applying the Dice coefficient. Sixty-nine isolates from piglets were isolated in this study. Two isolates from slaughter pigs and 73 isolates from humans were isolated previously (Oka etal., 2012; Asai etal., 2013). ATCC strains were used as control strains.
(P2 and P3; Figure 1). Although the prevalence of $C$. difficile was relatively low in slaughter pigs, the presence of healthy pigs carrying this pathogen in slaughterhouses poses a significant potential for the contamination of meats and subsequent human infection (Weese et al., 2011).

The current study showed that several strains could be isolated from a single sample. In many cases, each of these isolates yielded different PCR ribotypes. These results suggest that various types of $C$. difficile might co-exist in the piglet intestine. The most prevalent PCR ribotype in this study was P1. This ribotype indicated several toxin gene profiles. Previously, one PCR ribotype indicated the same toxin gene profile, except for a rare case (Martin et al., 2008). The second most prevalent PCR ribotype $\mathrm{P} 2$ was then non-toxigenic PCR ribotype 038 . The prevalence of this ribotype has not been reported in other countries in piglet. In European countries, PCR ribotype 078 derived from piglets was the most prevalent PCR ribotype (Keel et al., 2007; Hopman et al., 2011; Schneeberg et al., 2013). These results suggest that the distribution of this PCR ribotype in Japan was unique. Although the toxin gene profile of $\mathrm{P} 1$ was unusual, this ribotype should be monitored in Japanese pigs.

This study demonstrated that toxigenic $C$. difficile (Toxin $\mathrm{A}^{+} \mathrm{B}^{+}$) were isolated with high prevalence $(61.0 \%)$ from piglets in Japan. The binary toxin genes, which contribute to the severity of infection (Bacci etal., 2011), were found in $26 \%$ of the isolates. Some $C$. difficile isolates were also resistant to the tested antimicrobials which are linked to antibiotic-associated diarrhea caused by C. difficile (Bartlett and Gerding, 2008). 
Table 4 | Relationship between the PCR ribotype and the toxin gene profile.

\begin{tabular}{lllll}
\hline PCR & \multirow{2}{*}{$\begin{array}{l}\text { No. of } \\
\text { Ribotypes }\end{array}$} & \multicolumn{2}{c}{ Toxin $\mathbf{A}^{+} \mathbf{B}^{+}$} & \multirow{2}{*}{ Toxin $\mathbf{A}^{-} \mathbf{B}^{-} \mathbf{C D T}^{-}$} \\
\cline { 3 - 4 } & isolates & $\mathbf{C D T}^{+}$ & $\mathbf{C D T}^{-}$ & \\
\hline P1 & 34 & 8 & 9 & 17 \\
P2 & 20 & 0 & 0 & 20 \\
P3 & 12 & 12 & 0 & 0 \\
P4 & 9 & 0 & 9 & 0 \\
P5 & 6 & 0 & 6 & 0 \\
P6 & 5 & 5 & 0 & 0 \\
P7 & 3 & 0 & 3 & 0 \\
P8 & 3 & 0 & 3 & 0 \\
P9 & 2 & 2 & 0 & 0 \\
P10 & 2 & 0 & 2 & 0 \\
P11 & 1 & 1 & 0 & 0 \\
P12 & 1 & 0 & 1 & 0 \\
P13 & 1 & 0 & 1 & 0 \\
P14 & 1 & 0 & 1 & 0 \\
\hline
\end{tabular}

Table 5 | For each strain, the results of the optimized MLVA for each of the 7 loci.

\begin{tabular}{|c|c|c|c|c|c|c|c|c|}
\hline \multirow[t]{2}{*}{$\begin{array}{l}\text { Isolate } \\
\text { No. }\end{array}$} & \multirow[t]{2}{*}{ Farm } & \multicolumn{7}{|c|}{$\begin{array}{l}\text { MLVA result (No. of tandem repeats } \\
\text { for indicated locus) }\end{array}$} \\
\hline & & $A 6_{c d}$ & $B 7_{c d}$ & $c 6_{c d}$ & $E 7_{c d}$ & $F 3_{c d}$ & $\mathbf{G}_{\mathrm{cd}}$ & $\mathrm{H} \mathbf{9}_{\mathrm{cd}}$ \\
\hline 1 & $E$ & NA & 22 & 37 & 8 & 4 & 10 & 2 \\
\hline 2 & $\mathrm{E}$ & NA & 22 & 37 & 8 & 4 & 10 & 2 \\
\hline 3 & $\mathrm{E}$ & NA & 22 & 37 & 8 & 4 & 10 & 2 \\
\hline 4 & $\mathrm{~F}$ & NA & 8 & 36 & 9 & 4 & 4 & 2 \\
\hline 5 & $\mathrm{~J}$ & NA & 22 & 34 & 8 & 4 & 11 & 2 \\
\hline 6 & $\mathrm{~J}$ & NA & 21 & 36 & 8 & 4 & 11 & 2 \\
\hline 7 & $\mathrm{~J}$ & NA & 22 & 36 & 8 & 4 & 11 & 2 \\
\hline 8 & $\mathrm{~J}$ & NA & 22 & 35 & 8 & 4 & 11 & 2 \\
\hline 9 & $\mathrm{~J}$ & NA & 18 & 36 & 8 & 4 & 11 & 2 \\
\hline 10 & $\mathrm{~J}$ & NA & 22 & 35 & 8 & 4 & 11 & 2 \\
\hline 11 & $\mathrm{~J}$ & NA & 22 & 36 & 8 & 4 & 11 & 2 \\
\hline 12 & $\mathrm{~J}$ & NA & 21 & 36 & 8 & 4 & 11 & 2 \\
\hline $12 \mathrm{EN}^{\mathrm{a}}$ & & NA & 25 & 33 & 8 & 4 & 12 & 2 \\
\hline
\end{tabular}

NA, not applicable.

a This isolate was derived from slaughter pig (Asai et al., 2013).

Comparing the antimicrobial susceptibility between piglet isolates and human clinical isolates, the resistance rate of piglet isolates was lower than that of human clinical isolates. These findings suggest that human clinical isolates are frequently exposed to the antimicrobials in clinical practices, resulting in a higher incidence of resistance. Moreover, the low percentage of ceftriaxone resistance $(6.0 \%)$ in swine isolates is likely due to the

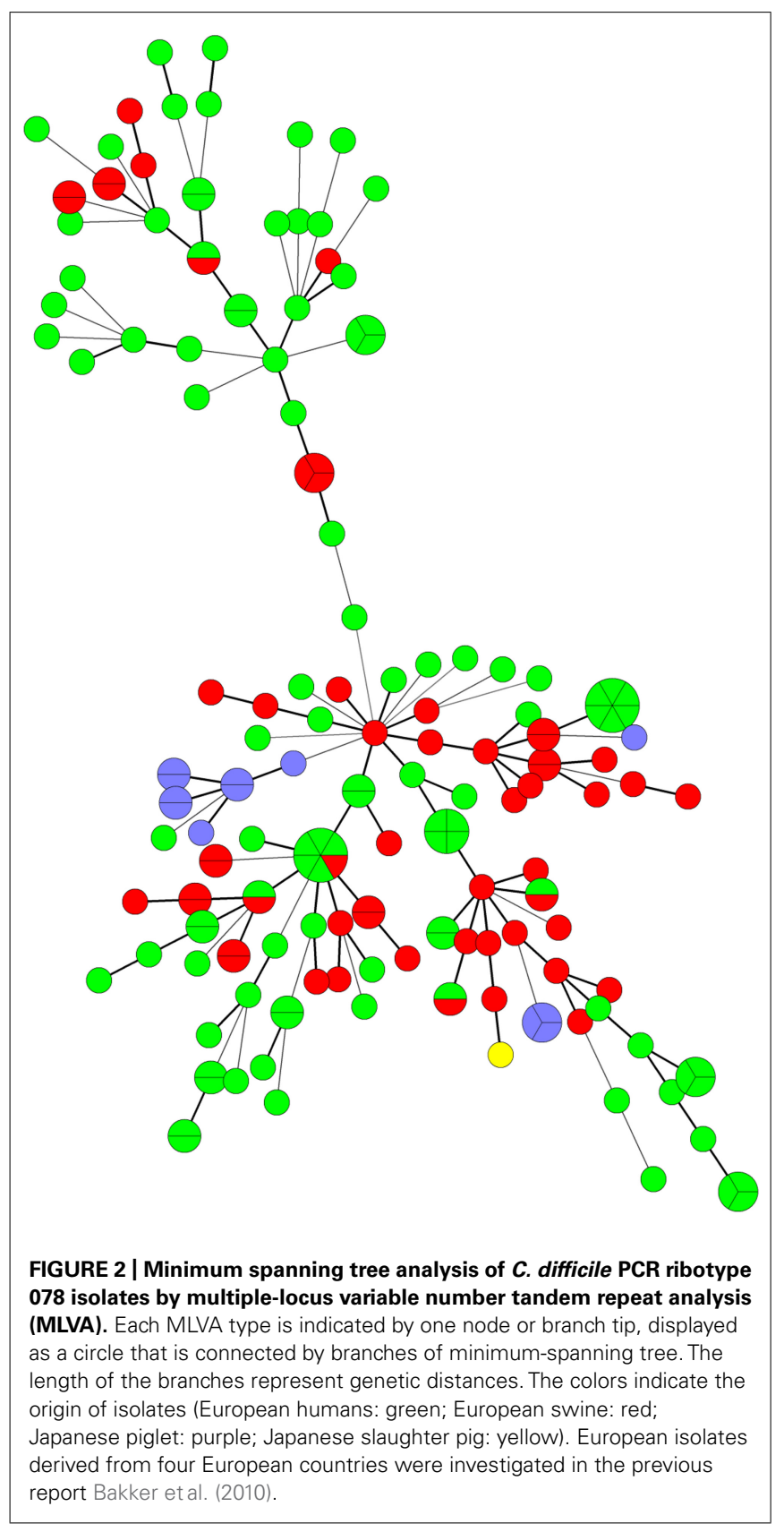

rare usage of cephalosporin in pigs (Ministry of Agriculture Forestry and Fisheries $[\mathrm{MAFF}], 2012)$. The hypervirulent PCR ribotype 078 has caused serious outbreaks in humans worldwide and has been detected in both humans and pigs among European countries (Bakker etal., 2010; Keessen et al., 2011). Currently, PCR ribotype 078 is the third dominant PCR ribotype among Japanese piglets, although it has not been isolated in the human clinical setting in Japan (Collins et al., 2013). Our results indicate that piglets are potential reservoirs of toxigenic and antimicrobial-resistant $C$. difficile, including PCR ribotype 078, in Japan.

Clostridium difficile can survive in the environment for several months because of its spore-forming ability (Kim et al., 1981). 
Vermin can also play a role in the spread and transmission of $C$. difficile within pig farms and to other locations (Burt et al., 2012). In addition, as the manure of pigs, including piglets, are used to fertilize crops, $C$. difficile can pollute the soil and contaminate vegetables (al Saif and Brazier, 1996). Therefore, C. difficile can be readily transferred to humans via both animal products and vegetables. In addition, pigs are sometimes kept as pet. The pets are thought to pose a high risk transmission of $C$. difficile to humans, because of close contact with humans. In the current study, C. difficile was not isolated from farm $\mathrm{F}$. Therefore, reducing $C$. difficile infection in piglets is possible. However, we could not clarify the reason for the negative test for $C$. difficile in farm $\mathrm{F}$, and so a future study should assess the cause of this observation. To minimize the risk posed by C. difficile, it is necessary to develop effective hygiene management practices to aid in the limitation of the dissemination of $C$. difficile.

It is important to establish an epidemiological analysis for C. difficile to clarify its origin in pigs in Japan. MLVA revealed that swine isolates of PCR ribotype 078 in Japan were genetically related to European isolates from both humans and pigs (Bakker et al., 2010). In addition, Japanese isolates of PCR ribotype 078 , except for one strain isolated from a slaughter pig (Debast et al., 2009), were toxinotype $V$ and contained a 39-base pair deletion in the toxin regulator gene $(t c d C)$, the same as European PCR ribotype 078 isolates (Pirs et al., 2008). Many breeding pigs have been imported to Japan from European and North American countries (Baba et al., 2010). In European countries, the isolation of PCR ribotype 078 from piglets was more prevalent compared with the current study (Keel et al., 2007; Hopman et al., 2011; Schneeberg et al., 2013). The spread of pathogenic bacteria such as methicillin-resistant Staphylococcus aureus could be related to the global distribution of the pigs (Espinosa-Gongora et al., 2012). These results raise the possibility that $C$. difficile PCR ribotype 078 was brought to Japan via the import of breeding pigs.

In conclusion, 14 PCR ribotypes of $100 \mathrm{C}$. difficile strains isolated from piglets were distinguishable from those of 73 human clinical isolates included in this study. As all human clinical isolates were isolated from only two hospitals in Tokyo, large-scale studies are essential to clarify the relatedness between human clinical isolates and animal isolates in Japan. This study revealed that C. difficile, prevalent among Japanese pigs, is a potential risk for antibiotic-associated diarrhea. Although PCR ribotype 078 were isolated in Japanese piglets, a unique distribution of PCR ribotypes was observed in Japan. Continuous surveillance of $C$. difficile PCR ribotype 078 among human clinical isolates is also necessary.

\section{ACKNOWLEDGMENTS}

We thank the staff of The Japanese Association of Swine Veterinarians for providing piglet fecal samples. This work was supported by JSPS KAKENHI Grant Number 26860441.

\section{REFERENCES}

al Saif, N., and Brazier, J. S. (1996). The distribution of Clostridium difficile in the environment of South Wales. J. Med. Microbiol. 45, 133-137. doi: 10.1099/00222615-45-2-133

Alvarez-Perez, S., Blanco, J. L., Bouza, E., Alba, P., Gibert, X., Maldonado, J., et al. (2009). Prevalence of Clostridium difficile in diarrhoeic and non-diarrhoeic piglets. Vet. Microbiol. 137, 302-305. doi: 10.1016/j.vetmic.2009. 01.015

Asai, T., Usui, M., Hiki, M., Kawanishi, M., Nagai, H., and Sasaki, Y. (2013). Clostridium difficile isolated from the fecal contents of swine in Japan. J. Vet. Med. Sci. 75, 539-541. doi: 10.1292/jvms.12-0353

Baba, K., Ishihara, K., Ozawa, M., Tamura, Y., and Asai, T. (2010). Isolation of meticillin-resistant Staphylococcus aureus (MRSA) from swine in Japan. Int. J. Antimicrob. Agents 36, 352-354. doi: 10.1016/j.ijantimicag.2010. 06.040

Bacci, S., Molbak, K., Kjeldsen, M. K., and Olsen, K. E. (2011). Binary toxin and death after Clostridium difficile infection. Emerg. Infect. Dis. 17, 976-982. doi: 10.3201/eid/1706.101483

Bakker, D., Corver, J., Harmanus, C., Goorhuis, A., Keessen, E. C., Fawley, W. N., et al. (2010). Relatedness of human and animal Clostridium difficile PCR ribotype 078 isolates determined on the basis of multilocus variable-number tandemrepeat analysis and tetracycline resistance. J. Clin. Microbiol. 48, 3744-3749. doi: 10.1128/JCM.01171-10

Bartlett, J. G., and Gerding, D. N. (2008). Clinical recognition and diagnosis of Clostridium difficile infection. Clin. Infect. Dis. 46(Suppl. 1), S12-S18. doi: $10.1086 / 521863$

Bauer, M. P., Notermans, D. W., van Benthem, B. H., Brazier, J. S., Wilcox, M. H., Rupnik, M., et al. (2011). Clostridium difficile infection in Europe: a hospital-based survey. Lancet 377, 63-73. doi: 10.1016/S0140-6736(10) 61266-4

Burt, S. A., Siemeling, L., Kuijper, E. J., and Lipman, L. J. (2012). Vermin on pig farms are vectors for Clostridium difficile PCR ribotypes 078 and 045 . Vet. Microbiol. 160, 256-258. doi: 10.1016/j.vetmic.2012.05.014

Clinical Laboratory Standards Institute [CLSI]. (2007). Methods for Antimicrobial Susceptibility Testing of Anaerobic Bacteria; Approved Standard-Seventh Edition. CLSI Document M11-A7. Wayne, PA: Clinical Laboratory Standards Institute.

Collins, D. A., Hawkey, P. M., and Riley, T. V. (2013). Epidemiology of Clostridium difficile infection in Asia. Antimicrob. Resist. Infect. Control. 2, 21. doi: 10.1186/2047-2994-2-21

Debast, S. B., van Leengoed, L. A., Goorhuis, A., Harmanus, C., Kuijper, E. J., and Bergwerff, A. A. (2009). Clostridium difficile PCR ribotype 078 toxinotype $\mathrm{V}$ found in diarrhoeal pigs identical to isolates from affected humans. Environ. Microbiol. 11, 505-511. doi: 10.1111/j.1462-2920.2008.01790.x

Espinosa-Gongora, C., Broens, E. M., Moodley, A., Nielsen, J. P., and Guardabassi, L. (2012). Transmission of MRSA CC398 strains between pig farms related by trade of animals. Vet. Rec. 170, 564. doi: 10.1136/vr.100704

Honda, H., Yamazaki, A., Sato, Y., and Dubberke, E. R. (2014). Incidence and mortality associated with Clostridium difficile infection at a Japanese tertiary care center. Anaerobe 25, 5-10. doi: 10.1016/j.anaerobe.2013.10.004

Hopman, N. E., Keessen, E. C., Harmanus, C., Sanders, I. M., van Leengoed, L. A., Kuijiper, E. J., et al. (2011). Acquisition of Clostridium difficile by piglets. Vet. Microbiol. 149, 186-192. doi: 10.1016/j.vetmic.2010.10.013

Kato, H., Kato, N., Katow, S., Maegawa, T., Nakamura, S., and Lyerly, D. M. (1999). Deletions in the repeating sequences of the toxin A gene of toxin A-negative, toxin B-positive Clostridium difficile strains. FEMS Microbiol. Lett. 175, 197-203. doi: 10.1016/S0378-1097(99)00196-2

Kato, H., Kato, N., Watanabe, K., Iwai, N., Nakamura, H., Yamamoto, T., et al. (1998). Identification of toxin A-negative, toxin B-positive Clostridium difficile by PCR. J. Clin. Microbiol. 36, 2178-2182.

Keel, K., Brazier, J. S., Post, K. W., Weese, S., and Songer, J. S. (2007). Prevalence of PCR ribotype among Clostridium difficile isolates from pigs, calves, and other species. J. Clin. Microbiol. 45, 1963-1964. doi: 10.1128/JCM. 00224-07

Keessen, E. C., Gaastra, W., and Lipman, L. J. (2011). Clostridium difficile infection in humans and animals, differences and similarities. Vet. Microbiol. 153, 205-217. doi: 10.1016/j.vetmic.2011.03.020

Kikuchi, E., Miyamoto, Y., Narushima, S., and Itoh, K. (2002). Design of species-specific primers to identify 13 species of Clostridium harbored in human intestinal tracts. Microbiol. Immunol. 46, 353-358. doi: 10.1111/j.13480421.2002.tb02706.x

Kim, K. H., Fekety, R., Batts, D. H., Brown, D., Cudmore, M., Silva, J., et al. (1981). Isolation of Clostridium difficile from the environment and contacts of patients with antibiotic-associated colitis. J. Infect. Dis. 143, 42-50. doi: 10.1093/infdis/143.1.42 
Knight, D. R., Thean, S., Putsathit, P., Fenwick, S., and Riley, T. V. (2013). Crosssectional study reveals high prevalence of Clostridium difficile non-PCR ribotype 078 strains in Australian veal calves at slaughter. Appl. Environ. Microbiol. 79, 2630-2635. doi: 10.1128/AEM.03951-12

Martin, H., Willey, B., Low, D. E., Staempfli, H. R., McGeer, A., Boerlin, P., et al. (2008). Characterization of Clostridium difficile strains isolated from patients in Ontario, Canada, from 2004 to 2006. J. Clin. Microbiol. 46, 2999-3004. doi 10.1128/JCM.02437-07

Ministry of Agriculture Forestry and Fisheries [MAFF]. (2012). Sales Amount of Medicines, Quasidrugs, and Medical Devices for Animal Use 2005-2010. Tokyo: Japan Veterinary Products Association.

Norman, K. N., Harvey, R. B., Scott, H. M., Hume, M. E., Andrews, K., and Brawley, A. D. (2009). Varied prevalence of Clostridium difficile in an integrated swine operation. Anaerobe 15, 256-260. doi: 10.1016/j.anaerobe.2009.09.006

Oka, K., Osaki, T., Hanawa, T., Kurata, S., Okazaki, M., Manzoku, T., et al. (2012). Molecular and microbiological characterization of Clostridium difficile isolates from single, relapse, and reinfection cases. J. Clin. Microbiol. 50, 915-921. doi: 10.1128/JCM.05588-11

Persson, S., Torpdahl, M., and Olsen, K. E. (2008). New multiplex PCR method for the detection of Clostridium difficile toxin $\mathrm{A}(\mathrm{tcd} \mathrm{A})$ and toxin $\mathrm{B}(\mathrm{tcdB})$ and binary toxin $(\mathrm{cdtA} / \mathrm{cdtB})$ genes applied to a Danish strain collection. Clin. Microbiol. Infect. 14, 1057-1064. doi: 10.1111/j.1469-0691.2008.02092.x

Pirs, T., Ocepek, M., and Rupnik, M. (2008). Isolation of Clostridium difficile from food animals in Slovenia. J. Med. Microbiol. 57, 790-792. doi: 10.1099/jmm.0.47669-0

Richards, M., Knox, J., Elliott, B., Mackin, K., Lyras, D., Waring, L. J., et al. (2011). Severe infection with Clostridium difficile PCR ribotype 027 acquired in Melbourne, Australia. Med. J. Aust. 194, 369-371.

Rupnik, M., Brazier, J. S., Duerden, B. I., Grabnar, M., and Stubbs, S. L. (2001). Comparison of toxinotyping and PCR ribotyping of Clostridium difficile strains and description of novel toxinotypes. Microbiology 147, 439-447.

Rupnik, M., Wilcox, M. H., and Gerding, D. N. (2009). Clostridium difficile infection: new developments in epidemiology and pathogenesis. Nat. Rev. Microbiol. 7, 526-536. doi: 10.1038/nrmicro2164
Schneeberg, A., Neubauer, H., Schmock, G., Baier, S., Harlizius, J., Nienhoff, H., etal. (2013). Clostridium difficile genotypes in piglet populations in Germany. J. Clin. Microbiol. 51, 3796-3803. doi: 10.1128/JCM. 01440-13

Spigaglia, P., and Mastrantonio, P. (2002). Molecular analysis of the pathogenicity locus and polymorphism in the putative negative regulator of toxin production (TcdC) among Clostridium difficile clinical isolates. J. Clin. Microbiol. 40, 3470 3475. doi: 10.1128/JCM.40.9.3470-3475.2002

Stubbs, S. L., Brazier, J. S., O’Neill, G. L., and Duerden, B. I. (1999). PCR targeted to the 16S-23S rRNA gene intergenic spacer region of Clostridium difficile and construction of a library consisting of 116 different PCR ribotypes. J. Clin. Microbiol. 37, 461-463.

Weese, J. S., Rousseau, J., Deckert, A., Gow, S., and Reid-Smith, R. J. (2011). Clostridium difficile and methicillin-resistant Staphylococcus aureus shedding by slaughter-age pigs. BMC Vet. Res. 7:41. doi: 10.1186/1746-6148-7-41

Conflict of Interest Statement: The authors declare that the research was conducted in the absence of any commercial or financial relationships that could be construed as a potential conflict of interest.

Received: 24 July 2014; accepted: 12 September 2014; published online: 08 October 2014.

Citation: Usui M, Nanbu Y, Oka K, Takahashi M, Inamatsu T, Asai T, Kamiya S and Tamura $Y$ (2014) Genetic relatedness between Japanese and European isolates of Clostridium difficile originating from piglets and their risk associated with human health. Front. Microbiol. 5:513. doi: 10.3389/fmicb.2014.00513

This article was submitted to Infectious Diseases, a section of the journal Frontiers in Microbiology.

Copyright (0) 2014 Usui, Nanbu, Oka, Takahashi, Inamatsu, Asai, Kamiya and Tamura This is an open-access article distributed under the terms of the Creative Commons Attribution License (CC BY). The use, distribution or reproduction in other forums is permitted, provided the original author(s) or licensor are credited and that the original publication in this journal is cited, in accordance with accepted academic practice. No use, distribution or reproduction is permitted which does not comply with these terms. 